\title{
Reflections on Learning How to Teach Mathematics: The Initial Training of Kindergarten Teachers*
}

\author{
Ching-Shu Chen \\ Center for Teacher Education, Tainan University of Technology, Tainan, Taiwan \\ Email: tg0002@mail.tut.edu.tw
}

Received 19 October 2013; accepted 10 July 2015; published 13 July 2015

Copyright (C) 2015 by author and Scientific Research Publishing Inc.

This work is licensed under the Creative Commons Attribution International License (CC BY).

http://creativecommons.org/licenses/by/4.0/

c) (i) Open Access

\begin{abstract}
Teacher training programs have recently embraced the concept of reflection in the preparation of capable professionals for educational practice. This study included reflection as part of the design of a teaching-learning program developed to train pre-service kindergarten teachers to teach mathematics. The participants in this study were 40 pre-service teachers who enrolled in a two-year program of kindergarten teacher education in Taiwan. This study was designed to assess whether including reflection as a component of the teaching-learning program enabled teachers to better promote their mathematics learning and teaching competence. The results of this study show that engaging in reflection and preparing a learning portfolio can help pre-service teachers gain mathematical knowledge and learn more about their own teaching methods. The results also suggest that mathematical knowledge and pedagogical content knowledge can increase over time. Finally, this study discusses how to apply reflection in teacher-education programs in order to promote the successful professional development of pre-service teachers.
\end{abstract}

\section{Keywords}

Reflection, Pre-Service Teacher, Childhood Mathematics

\section{Introduction}

Early childhood education is becoming an increasingly common experience for young children in Taiwan. Many children in school are ready and eager to learn mathematics; however, whether the teachers are adequately prepared to teach them remains a question. Although various teacher preparation programs provide opportunities to

*Reflection works in Teacher Education Program. 
develop better ways to prepare teachers, most of them do not appear to provide students majoring in early childhood mathematics education with the adequate preparation for teaching young children domain-specific knowledge (Isenberg, 2000), particularly mathematics (Copley, 2004; Sarama, DiBiase, Clements, \& Spitler, 2004). Mathematical knowledge is a critical factor of effective teaching, especially for a pre-service kindergarten teacher, given that teacher content knowledge often tends to overshadow pedagogical content knowledge about the ways through which students learn and develop in the domain of interest (Nathan \& Petrosino, 2003). Many kindergarten teachers in Taiwan may have experienced underachievement in mathematics when they were in high school, which may have negatively affected their attitudes toward teaching mathematics. Kindergarten teachers may also have difficulty in identifying mathematical values and may prefer not to teach mathematics in their classes (Clements, 2004). Furthermore, teacher educational preparation programs include few mathematics courses, which may influence the perspective of teachers regarding teaching mathematics. Rowland, Huchstep, and Thwaites (2005) affirmed that pre-service teacher education programs should aim to develop the mathematical knowledge of teachers and their attitudes toward teaching mathematics. There is a concern that pre-service kindergarten teachers may fail to include mathematics as part of their teaching curriculum, thereby causing young children to miss opportunities to learn mathematics. To address these concerns, this study introduced a professional training program to pre-service kindergarten teachers that aimed to improve their mathematical knowledge and mathematics teaching methods through reflections. This study also investigated how the perceptions of teachers regarding the teaching of mathematics and the learning of mathematics were affected by their experiences in the program. This study examined the following research question: Can the participation of pre-service kindergarten teachers in the program improve their mathematics knowledge and develop their mathematics teaching abilities?

\section{Reflection of Use}

Mathematics is a way of thinking, and mathematics teachers must guide students to develop their thinking and reasoning capabilities. Although future teachers must be prepared for these circumstances, it may seem impossible for the teacher educators to provide them with the background knowledge necessary to face all of the diverse situations and aspects of their future profession. Previous research has shown that pre-service teachers should be trained to be critical of their own practices and that reflection should be one of the most important aspects of their training (Artzt, 1999; Harrington, Quinn-Leering, \& Hodson, 1996). Schön (1987) asserted that reflection is a way to develop professional knowledge.

\subsection{Reflection Improves Mathematical Knowledge and Teaching Competence}

Reflection is a method that can be used to improve professional skills in all areas; it can also help teachers to build professional competence (van Manen, 1991). Reflection helps teachers become active learner. The reflection process occurs through classroom discourse and activities, as well as through the overall learning process. Providing pre-service teachers with face-to-face peer interactions regarding mathematical knowledge and teaching in the classroom is necessary to stimulate deep reflection (Schön, 1987; Bean \& Stevens, 2002; Çimer, Çimer, \& Vekli, 2013). Peer learning is also an effective technique to enhance pre-service teachers’ teaching skills, self-confidence, sense of professionalism, and ability to share feedback when they teach (Arnau, Kahrs, \& Kruskamp, 2004; Hasbrouck, 1997; Jenkins, Hamrick, \& Todorovich, 2002; Lu, 2010). However, reflecting on the way students collaborate in learning and how they can improve their learning process is equally important. To accomplish this, teacher educators should design a module in their training programs to encourage pre-service teachers to discuss and reflect on the learning process, which may consequently help pre-service kindergarten teachers become better professionals.

\subsection{Learning and Teaching through Reflection}

The concept of reflection adopted in this study is an implicit act that requires the appropriate tools to measure the responses of pre-service teachers regarding their knowledge of teaching and learning mathematics in the initial training program. Creating a portfolio is one way to capture teacher reflection and improve professional development. According to Chamoso and Cáceres (2009), a portfolio is a useful tool for collecting, selecting, and organizing the work of pre-service teachers in a way that demonstrates how much teachers have learned and 
reflected. In this study, collecting records of pre-service teachers' learning and reflection involved obtaining information from interviews, video analyses, and field notes.

\section{Research Design}

The goal of this study was to help pre-service kindergarten teachers gain mathematical knowledge and appropriate methods of teaching mathematics to young children through the use of reflection. In the class, pre-service kindergarten teachers engaged in productive, unguided peer discourse to understand more clearly the methods of gaining mathematical knowledge, teaching mathematics, and confirming the importance of mathematics. This study demonstrated the contribution of the program in shifting the perspective of the teachers concerning mathematics. The identification of the discourse process was interwoven in peer collaboration. In addition, this study demonstrated the contribution of the program and the use of peer discourse in positively shifting the perspective of the teachers with regards to mathematics. Pre-service teachers applied and recorded learning data in a portfolio, and the results demonstrated the effectiveness of peer discourse and learning.

\subsection{Module}

The module used in this study for developing the teachers' mathematics teaching knowledge was based on the connection of various childhood life experiences that could involve mathematical concepts, including number operations and geometric shapes. The 36-hour module was conducted in two-hour sessions during the pre-service teachers' first year of study in teacher education. The objective of this module was to develop capabilities related to specific competencies in the training of professional mathematics teachers. The module included 18 weeks of teaching-learning lessons to develop the professional competencies of pre-service teachers. To help pre-service teachers practice mathematical concepts, various activities were provided during the sessions of early childhood mathematics. The pre-service teachers were required to write their reflections after each session, focusing on four categories: curriculum, peer learning, mathematical knowledge, and critical reflection. In-class peer learning was used to improve pre-service teachers' mathematical knowledge and teaching in the professional programs. In math class, participants engaged in productive peer discourse, gained mathematical knowledge, learned how to teach mathematics, and affirmed the value of mathematics.

\subsection{Participants}

This study was conducted during the 2011-2012 academic year with a group of pre-service kindergarten teachers in a teacher education program at a university. These pre-service teachers had already completed their second year of university and were being trained to teach mathematics at the kindergarten level. Participating in a course entitled "Mathematics" in the teacher education program, the pre-service teachers worked in pairs on class activities designed to instruct mathematics to young children. The study sample included 40 teachers (1 man and 39 women) who completed all of the module activities. The average age of the participants was 21.7 years old.

\subsection{The Role of the Researcher}

The researcher in this study played the role of curriculum designer, observer, and activity leader. Therefore, the researcher's responsibilities included designing the mathematics activities for pre-service kindergarten teachers, observing them in class, and leading the discussions. The data were analyzed through a multistage process that began with a written narrative based on field notes and mechanical recordings.

\subsection{Learning Objective}

To participate in the initial training process, pre-service kindergarten teachers must possess sufficient skills to teach the contents (know-how) in addition to theoretical knowledge (knowing). The learning objective was organized from two perspectives. Each perspective was divided into two sub-aspects (Hill, Ball, \& Schilling, 2008; Cáceres, Chamoso, \& Azcárate, 2010):

1) Mathematical knowledge

To know mathematical concepts, properties, and activities at the kindergarten level, and to experiment with 
mathematical content, exercise open activities, and establish relationships with other content or areas of knowledge.

2) Professional competence to teach kindergarten-level mathematics

To understand mathematics education to promote teaching and learning and apply one's knowledge to the teaching and learning of kindergarten-level mathematics content. Examples include applying lesson plans in class and designing creative activities to teach numbers and shapes.

\section{Data Collection and Analysis}

The data collection process in this study included observing the pre-service teachers who were practicing teaching methods in class, interviewing the pre-service teachers to determine their responses after each class, and analyzing videotape transcripts. The use of these various forms of evidence enabled the researcher to triangulate the results and improve their validity. Data were also obtained from the responses to provided scales.

\subsection{Survey Scales}

Two scales were provided to participants to assess the effectiveness of the learning program. After attending the program, the participants were evaluated by the researcher to determine their mathematical knowledge of level. The test consisted of 14 mathematical questions. All items were pre-tested by 120 teacher-candidates, and item responses were analyzed by the researcher, who selected only the items that fit the goal of teaching preschool mathematics for inclusion in the test. When the participants gave a correct answer to a question, they received 1 point, whereas when they provided an incorrect answer to a question, they did not receive any points. The resulting evaluation scores indicated whether the participants liked to teach mathematics, and whether their content knowledge and pedagogy were central to the knowledge required for childhood mathematics teaching. The Fennema-Sherman Mathematics Scales (Fennema \& Sherman, 1976) was used to evaluate the participants' attitudes, given that their attitudes toward learning mathematics influenced their performance in mathematics. This scale has five subscales, which include "Attitudes toward success in math," "Math anxiety," "Motivation," "Usefulness of math," and "Confidence in learning math," and responses are recorded using a Likert.

\subsection{Ranking Scales}

To assess the level of reflection, the teachers were asked to write their learning reflections in the university classroom. After each class, the participants had to complete an assignment that included structured questions to help them rank their weekly learning reflections on scales. The level of reflection depended on the involvement of the pre-service teacher in the learning process, and was ranked based on the following five levels (1 - 5) adapted from Chamoso, Cáceres, and Azcárate (2012): generality, when the pre-service teacher did not reflect on the process; description, when the pre-service teacher described aspects related to the teaching-learning process without getting involved (i.e., they presented a summary of what was accomplished during an activity); argumentation, when the pre-service teacher argued, justified, or drew conclusions about the teaching-learning process; contribution, when the pre-service teacher contributed to improving their teaching-learning process and teaching practice; and specialty, when the pre-service teacher got involved in the activities and presented creative ideas to integrate art to enhance teaching and learning. The participants were classified based on the levels of reflection presented in Table 1.

\subsection{Context}

The learning content in this program included information on early mathematics and pedagogy. The teachertraining program was organized into two parts: the first part was designed to introduce the participants to learning about mathematics, and the second part focused on peer learning in the practice of teaching.

This study raised an important question: What do pre-service kindergarten teachers need to know mathematics content, or what does effective teaching require in terms of content understanding? Activities were designed to attract pre-service teachers to join the program; additionally, program participants were encouraged to put their learning into action. This program provided content on elementary-level numbers and geometric shapes. As effective teaching requires content understanding, student teachers must first know the material. Therefore, the mathematical concepts that the participants encountered included distinguishing cardinal numbers, using 
Table 1. Examples of the levels of reflection.

\begin{tabular}{ccc}
\hline Level & Example & Code \\
\hline G (1) & When we played porkers, we all went crazy! & C3-S25 \\
D (2) & Counting numbers, we counted on (number sequence in order) that we haven’t found this way! & C1-S23 \\
A (3) & I could identify sequences and patterns from different arrays of objects. & C2-S2 \\
C (4) & We changed the methodology to solve problems in arithmetic. & C5-S12 \\
S (5) & We applied tangrams to make different kinds of animals. & C11-S30 \\
\hline
\end{tabular}

patterns or sequences to teach young children to discern even and odd numbers, number relationships, and base-ten numerical concepts.

The knowledge and pedagogy of teaching numbers and geometric shapes were delivered through various activities. All activities were hands-on activities or games to motivate pre-service kindergarten teachers' mathematics learning. Table 2 lists the content taught and the corresponding activities.

\section{Result and Discussion}

Evident in Table 3, the program was designed to expand the mathematical knowledge of pre-service teachers. The results of this study challenge Isenberg's (2000) finding that most education programs cannot adequately prepare early childhood teachers to teach domain-specific knowledge to young children. The program aimed to promote mathematical knowledge in pre-service teachers. From this perspective, did the pre-service teachers in the program indeed gain more mathematical knowledge and learn how to teach mathematics? By recording their reflections and conducting further exploration, were these pre-service teachers indeed able to improve their own teaching and learning processes?

Moreover, in their reflections, pre-service teachers referred to various aspects of the teaching and learning process. Table 4 shows that pre-service teachers referred more to learning (62\%) than to teaching (38\%) in their reflections; that is, they focused on what had occurred in the training classroom and not on what had created their knowledge. Furthermore, evident in Table 4, the statistical results of the pre-service teachers' responses to the program through the practice of reflection show that the pre-service teachers were more concerned about gaining mathematical knowledge (273) than teaching mathematics (167). Teachers focused more on gaining mathematical knowledge because of their need for more practical experience in teaching mathematics, not because they were already knowledgeable in the area of teaching.

The reflections of the pre-service teachers were organized according to the aspects of teaching and process development, or the aspects of learning that involved the pre-service teachers contributing to the process from a personal perspective. This first step allowed the deepening of their reflections on content or methodological aspects. The results of this study show that the pre-service teachers focused most of their attention on knowledge learning, rather than on practice (particularly on methodology; see Table 3), in which they mainly referred to mathematical knowledge. The training sessions in the university classroom were conducted using various methodologies with the aim of encouraging the pre-service teachers' active participation and knowledge-building. Therefore, the training sessions provided the pre-service teachers with useful instruments for their future professional work.

The results of this study show that the proposed teacher-training program provided the participants with the knowledge of how to teach young children by applying various strategies. However, teachers need further pedagogical content knowledge, as teaching in preschool does not solely require content knowledge.

The scores on the attitudes toward mathematics subscale were higher than the average score of the entire scale (38.59 > 30), which indicated that the program participants were interested in mathematics. Therefore, these results reveal strong identities regarding mathematics and a willingness to teach mathematics to young children.

This study was based on the assumption that mathematical attitudes affected the participation of student teachers in learning about and teaching mathematics through reflection. To understand the participants' attitudes toward mathematics, this study applied the Fennema-Sherman Mathematics Scales (Fennema \& Sherman, 1976) to survey the participants. The results of this survey reveal positive attitudes toward mathematics. Table 5 shows that the means of each subscale were over 30.00. The mathematical experience of the subjects did not 
Table 2. Content and corresponding activities in the program.

\begin{tabular}{ccc}
\hline week & Example & Code \\
\hline 1 & Quantities & Numbers in life \\
2 & Number sequence & Arrangement of number \\
3 & Even and odd numbers & Reference of number to items \\
4 & Parts and whole & Diagrams and objects \\
5 & Composition \& decomposition & Number rods and porkers \\
6 & Spatial location & Treasure map search \\
7 & Landmark reference & School map construction \\
8 & Points, lines, dimensions & Point connection drawing \\
9 & Geometric shapes & Square or round items search \\
10 & Two dimensions to three dimensions & Tangram construction \\
11 & Various cubes & Cube-making and playing with dice \\
\hline
\end{tabular}

Table 3. Pre-service teachers responses to the program.

\begin{tabular}{|c|c|c|c|c|c|c|c|c|}
\hline \multirow{2}{*}{$\begin{array}{c}\text { Items } \\
\text { Content }\end{array}$} & \multicolumn{2}{|c|}{ Curricula } & \multicolumn{2}{|c|}{ P-Learning } & \multicolumn{2}{|c|}{ M-Knowledge } & \multicolumn{2}{|c|}{ Practice } \\
\hline & M & SD & M & SD & M & $\mathrm{SD}$ & M & SD \\
\hline 1) Quantities & 4.18 & 0.90 & 4.55 & 0.82 & 3.98 & 0.92 & 4.58 & 0.78 \\
\hline 2) Nu-sequence & 4.37 & 1.06 & 4.48 & 0.99 & 3.32 & 1.31 & 4.70 & 1.15 \\
\hline 3) Even \& odd & 4.70 & 0.67 & 4.88 & 0.46 & 3.88 & 1.52 & 4.55 & 0.90 \\
\hline 4) Parts-whole & 4.55 & 0.67 & 4.90 & 0.63 & 4.02 & 1.75 & 4.68 & 0.53 \\
\hline 5) Composition & 4.63 & 0.67 & 4.90 & 0.44 & 4.30 & 1.04 & 4.73 & 0.60 \\
\hline 6) Spatial & 4.60 & 0.98 & 4.82 & 0.64 & 4.53 & 1.15 & 4.68 & 0.83 \\
\hline 7) Landmark & 4.80 & 0.41 & 4.94 & 0.32 & 3.83 & 1.43 & 4.63 & 0.98 \\
\hline 8) Point, line, dim & 4.70 & 0.88 & 4.48 & 1.4 & 3.93 & 1.87 & 4.77 & 0.62 \\
\hline 9) Geo-shapes & 4.85 & 0.53 & 4.75 & 0.67 & 3.53 & 1.45 & 4.73 & 0.64 \\
\hline 10) $2 \mathrm{D}-3 \mathrm{D}$ & 4.70 & 0.69 & 4.78 & 0.62 & 3.90 & 1.46 & 4.88 & 0.46 \\
\hline 11) Cubes & 4.72 & 0.68 & 4.90 & 0.44 & 4.35 & 1.10 & 4.78 & 0.62 \\
\hline Total & $\begin{array}{l}50.80 \\
(4.62)\end{array}$ & 3.92 & $\begin{array}{l}52.38 \\
(4.76)\end{array}$ & 3.36 & $\begin{array}{l}43.55 \\
(3.95)\end{array}$ & 8.63 & $\begin{array}{l}51.25 \\
(4.65)\end{array}$ & 3.75 \\
\hline
\end{tabular}

Table 4. Results of the pre-seervice teachers' reflections on the Program.

\begin{tabular}{lccccccccccccc} 
& R1 & R2 & R3 & R4 & R5 & R6 & R7 & R8 & R9 & R10 & R11 & Total \\
\hline Learning & 32 & 15 & 37 & 30 & 26 & 26 & 23 & 30 & 23 & 13 & 18 & 273 \\
Teaching & 8 & 25 & 3 & 10 & 14 & 14 & 17 & 10 & 17 & 27 & 22 & 167 \\
\hline
\end{tabular}

affect their learning in the program, although they still had low mathematics anxiety $(\mathrm{M}=32.91)$ and confidence $(\mathrm{M}=36.91)$. However, their previous achievements (47.38) and self-identification regarding mathematics (40.86) helped them to perform well in the program.

When the participants first began the program, most of them doubted their mathematics abilities. However, when they participated in the program activities, their attitudes toward mathematics changed. Their inability to neglect the importance of mathematics and their preferences to avoid teaching mathematics in their classes (Clements, 2004) also changed.

After the program, except for the attitudes of pre-service teachers, mathematical cognition and participant performance were better post-test than they were pre-test (Table 6). 
Table 5. Pre-service teachers’ attitudes twoard mathematics.

\begin{tabular}{ccc}
\hline Sub-scales & M & SD \\
\hline Attitudes toward success in math (achievement) & 47.38 & 5.34 \\
Math anxiety & 32.91 & 8.18 \\
Motivation & 36.52 & 7.57 \\
Usefulness of math & 40.86 & 7.09 \\
Confidence in learning math & 35.30 & 8.31 \\
\hline
\end{tabular}

Table 6. Test of the mathematicacl knowledge of pre-service teachers.

\begin{tabular}{cccccc} 
& N & M & SD & t & $P$ \\
\hline Pre-test & 41 & 9.25 & 1.706 & 5.42 & 0.000 \\
Post test & & 11.30 & 1.70 & & \\
\hline
\end{tabular}

The pre-service teachers revealed various aspects of the teaching and learning process in their reflections, such as how learning occurred or how teaching abilities were developed. Hence, while reflection is a method for developing professionals in all areas, it can prepare pre-service teachers by improving their professional mathematics competencies and attitudes toward mathematics. The results of this study confirm the suggestion of Schön (1987) that reflection can be used as a tool for building professional knowledge.

\section{Conclusion}

This study demonstrated the importance of reflection in the training of pre-service kindergarten teachers. Various assessments of each of the training sessions revealed that the pre-service teachers responded positively to their reflections. An analysis of the reflections of these pre-service teachers regarding the teaching and learning process through their learning portfolios showed that the pre-service teachers changed their perceptions about their professional development. However, the highest level of reflection, which involves the application of knowledge to the practice of teaching, requires further discussion.

\section{References}

Arnau, L., Kahrs, J., \& Kruskamp, B. (2004). Peer Coaching: Veteran High School Teachers Take the Lead on Learning. NASSP Bulletin, 88, 26-41. http://dx.doi.org/10.1177/019263650408863904

Artzt, A. F. (1999). A Structure to Enable Preservice Teachers of Mathematics to Reflect on Their Teaching. Journal of Mathematics Teacher Education, 2, 143-166. http://dx.doi.org/10.1023/A:1009999004407

Bean, T. W., \& Stevens, L.P. (2002). Scaffolding Reflection for Preservice and Inservice Teachers. Reflective Practice, 3, 205-218. http://dx.doi.org/10.1080/14623940220142343

Cáceres, M. J. Chamoso, J. M., \& Azcárate, P. (2010). Analysis of the Revisions That Pre-Service Teachers of Mathematics Make of Their Own Project Included in Their Learning Portfolio. Teaching and Teacher Education, 26, 1186-1195. http://dx.doi.org/10.1016/j.tate.2010.01.003

Chamoso, J. M., \& Cáceres, M. J. (2009). Analysis of the Reflections of Student Teachers of Mathematics When Working with Learning Portfolios in Spanish University Classrooms. Teaching and Teacher Education, 25, 198-206. http://dx.doi.org/10.1016/j.tate.2008.09.007

Chamoso, J. M., Cáceres, M. J., \& Azcárate, P. (2012). Reflection on the Teaching-Learning Process in the Initial Training of Teachers. Characterization of the Issues on Which Pre-Service Mathematics Teachers Reflect. Teaching and Teacher Education, 28, 154-164. http://dx.doi.org/10.1016/j.tate.2011.08.003

Çimer, A., Sabiha Odabaşi Çimer, S. O., \& Vekli, G. S. (2013). How Does Reflection Help Teachers to Become Effective Teachers? International Journal of Educational Research, 1, 133-149.

Clements, D. (2004). Geometric and Spatial Thinking in Early Childhood Education. In D. H. Clements, J. Sarama, \& A. M. DiBiase (Eds.), Engaging Young Children in Mathematics: Standards for Early Childhood Mathematics Education (pp. 267-297). Mahwah, NJ: Lawrence Erlbaum Associates.

Copley, J. V. (2004). The Early Childhood Collaborative: A Professional Development Model to Communicate and Imple- 
ment the Standards. In D. H. Clements, \& J. Sarama (Eds.), Engaging Young Children in Mathematics: Standards for Early Childhood Mathematics Education (pp. 401-414). Mahwah, NJ: Lawrence Erlbaum Associates.

Fennem, E., \& Sherman, J. A. (1976). Fennema-Sherman Mathematics Scales: Instruments Designed to Measure Attitudes toward the Learning of Mathematics by Males and Females. Journal for Research in Mathematics Education, 7, 324-326. http://dx.doi.org/10.2307/748467

Harrington, H., Quinn-Leering, K., \& Hodson, L. (1996). Written Case Analyses and Critical Reflection. Teaching and Teacher Education, 12, 25-37. http://dx.doi.org/10.1016/0742-051X(96)89078-0

Hasbrouck, J. E. (1997). Mediated Peer Coaching for Training Preservice Teachers. The Journal of Special Education, 31, 251-271. http://dx.doi.org/10.1177/002246699703100206

Hill, H. C., Ball, D. L., \& Schilling, S. G. (2008). Unpacking Pedagogical Content Knowledge: Conceptualizing and Measuring Teachers’ Topic-Specific Knowledge of Students. Journal for Research in Mathematics Education, 39, $372-400$.

Isenberg, J. P. (2000). The State of the Art in Early Childhood Professional Preparation. In D. Horm-Wingerd, \& M. Hyson (Eds.), New Teachers for a New Century: The Future of Early Childhood Professional Preparation (pp. 17-58). Washington DC: US Department of Education.

Jenkins, J. M., Hamrick, C., \& Todorovich, J. (2002). Peer Coaching: Implementation and Data Collection Tools. Journal of Physical Education, Recreation \& Dance, 73, 47-53. http://dx.doi.org/10.1080/07303084.2002.10607791

Lu, H. L. (2010). Research on Peer Coaching in Preservice Teacher Education-A Review of Literature. Teaching and Teacher Education, 26, 748-753. http://dx.doi.org/10.1016/j.tate.2009.10.015

Nathan, M., \& Petrosino, A. (2003). Expert Blind Spot among Pre-Service Teachers. American Educational Research Journal, 40, 905-928. http://dx.doi.org/10.3102/00028312040004905

Rowland, T., Huckstep, P., \& Thwaites, A. (2005). Elementary Teachers’ Mathematics Subject Knowledge: The Knowledge Quartet and the Case of Naomi. Journal of Mathematics Teacher Education, 8, 255-281. http://dx.doi.org/10.1007/s10857-005-0853-5

Sarama, J., Di Biase, A. M., Clements, D. H., \& Spitler, M. E. (2004). The Professional Development Challenge in Preschool Mathematics. In D. H. Clements, J. Sarama, \& A. M. Di Biase (Eds.), Engaging Young Children in Mathematics: Standards for Early Childhood Mathematics Education (pp. 415-446). Mahwah, NJ: Lawrence Erlbaum Associates Publishers.

Schön, D. A. (1987). Educating the Reflective Practitioner: Toward a New Design for Teaching and Learning in the Profession. San Francisco, CA: Jossey-Bass.

Van Manen, M. (1991). Reflectivity and the Pedagogical Moment: The Normativity of Pedagogical Thinking and Acting. Journal of Curriculum Studies, 23, 507-536. http://dx.doi.org/10.1080/0022027910230602 